\title{
EFEITO ALELOPÁTICO DE EXTRATOS DE CARQUEJA E CONFREI EM SEMENTES DE SOJA E MILHO
}

\author{
Allelopathic Effect of the Carqueja and Confrey Extract on \\ Soybean and Corn Seeds
}

\author{
Gustavo Claudino ${ }^{1}$ \\ Ruy Inácio Neiva de Carvalho²
}

\section{Resumo}

O objetivo desta pesquisa foi avaliar o efeito alelopático dos extratos brutos aquosos (EBA) da parte aérea de plantas de carqueja e de plantas inteiras de confrei sobre a germinação de sementes e crescimento de plântulas de soja e milho. Os tratamentos adotados foram cinco concentrações de EBA: 0, 50, 100, 150 e 200 g.L. ${ }^{-1}$ de material vegetal. Esta pesquisa foi realizada no Laboratório de Análise de Sementes do Campus São José dos Pinhais da Pontifícia Universidade Católica do Paraná, localizada no município de São José dos Pinhais, Paraná. O método de germinação utilizado para as sementes de soja e milho foi o de rolo de papel acondicionados em germinadora com temperatura de $25^{\circ} \mathrm{C}$ por um período de sete dias. As variáveis analisadas foram as seguintes: plântulas normais (\%); plântulas anormais (\%); sementes dormentes (\%); sementes duras (\%); e sementes mortas (\%). Houve efeito alelopático do extrato bruto aquoso de plantas inteiras de confrei na germinação de sementes de milho, de forma mais significativa quando utilizadas concentrações acima de 100 g. $\mathrm{L}^{-1}$. Houve efeito alelopático significativo do extrato bruto aquoso de plantas inteiras de confrei na germinação e crescimento de plântulas de soja e da parte aérea de plantas de carqueja na germinação e crescimento de plântulas de milho, mesmo em concentrações baixas. Houve efeito alelopático significativo do extrato bruto aquoso da parte aérea de plantas de carqueja na geminação e crescimento de plântulas de soja, de forma mais significativa quando utilizadas concentrações acima de 100 g.: $\mathrm{L}^{-1}$.

Palavras-chave: Alelopatia; Baccharis trimera; Symphytum officinale; Glycine Max; Zea mays.

\section{Abstract}

The objective of the present research is to evaluate the allelopathic effect of the crude aqueous extracts of the aerial part of the carqueja plants and of the entire plant of comfrey on the germination of seeds and on the growing of soybean and com in their embryological state. The treatments adopted were composed of five concentrations of EBA: 0, 50, 100, 150 and $200 \mathrm{~g}^{-\mathrm{L}^{-1}}$ of vegetative material. The research was carried out at São José dos Pinhais Campus of the Pontifícia Universidade Católica do Paraná, situated in the municipality of São José dos Pinhais - PR. The germination method utilized for the seeds (soybean and com) was the roll of paper suitably accommodated in a germination device preheated to the temperature of $25^{\circ} \mathrm{C}$ for as long as seven days. The variables analyzed were the following: normal plants in their embryological state (\%); abnormal plants in their embryological state (\%); dormantseeds (\%); hard seeds (\%); dead seeds (\%). It was found allelopathic effect of the crude aqueous extract of the entire plant of comfrey on the germination of corn seeds in a more significant way in concentrations over 100 g.L-1. It was found significant allelopathic effect of the crude aqueous extract of either the entire plant of comfrey on the germination and growing of soybean plants in their embryological state or of the aerial part of carqueja plants on the germination and growing of corn plants in their embryological state even in low concentrations. In a more considerable way, it was found significant allelopathic effect of the crude aqueous extract of the aerial part of carqueja plants on the germination and growing of soybean plants in their embryological state when the concentrations were over $100 \mathrm{~g} \cdot \mathrm{L}^{-1}$.

Keywords: Allelopathy; Baccharis trimera; Symphytum officinale; Glycine max; Zea mays.

1 Estudante de Agronomia. Centro de Ciências Agrárias e Ambientais da Pontifícia Universidade Católica do Paraná, BR 376, km 14. CEP 83.010-500. São José dos Pinhais-PR. claudino.gustavo@uol.com.br.

2 Eng. Agrônomo, Dr., Professor Titular do Curso de Agronomia, Centro de Ciências Agrárias e Ambientais, Pontifícia Universidade Católica do Paraná. ruy.carvalho@pucpr.br. 


\section{Introdução}

A utilização de herbicidas, em muitos casos, é a única alternativa para o controle de algumas espécies de plantas daninhas. Mesmo com os avanços mais recentes no controle de plantas invasoras, em especial o surgimento de novos herbicidas, ainda hoje esse item é apontado como limitador à implantação do sistema agrícola. Além das questões puramente tecnológicas, destaca-se a importância do fator econômico desse controle, pois as planilhas de custos de produção demonstram que esse componente pode representar $22 \%$ de todos os custos variáveis para a cultura da soja e $21 \%$ para a cultura do milho. Aliado a isso, existe também o aspecto ambiental, pois os herbicidas representam aproximadamente $61 \%$ de todos defensivos comercializados no estado do Paraná (EMATER, 2004).

Uma alternativa ao uso dos herbicidas, inseticidas e nematicidas é a aplicação de tecnologias relacionadas à atividade dos aleloquímicos das plantas medicinais, que provém do metabolismo secundário porque, na evolução das plantas, representaram alguma vantagem contra a ação de microrganismos, vírus, insetos e outros patógenos ou predadores, seja inibindo a ação destes ou estimulando o crescimento ou desenvolvimento das plantas (FERREIRA; ÁQUILA, 2000).

Os metabólitos secundários participam de importantes funções vitais como mediadores de interações ecológicas. Eles têm função de garantir a sobrevivência de organismos particulares em ambientes hostis, onde muitos organismos competem uns com os outros. As fitoalexinas, por exemplo, são barreiras químicas responsáveis pela resistência das plantas ao ataque de microrganismos causadores de doenças (CASTRO; FERREIRA, 2001).

Todas as plantas produzem metabólitos secundários, que variam em qualidade e quantidade de espécie para espécie, ou de um local de ocorrência ou ciclo de cultivo para outro, pois muitos deles têm sua síntese desencadeada por eventuais vicissitudes a que as plantas estão expostas. A resistência ou tolerância aos metabólitos secundários que funcionam como aleloquímicos é mais ou menos específica, existindo espécies mais sensíveis que as outras (FERREIRA; AQUILA, 2000).

Algumas plantas com efeito inibidor sobre plantas invasoras também podem inibir a germinação de plantas de interesse, fato que limitaria o seu uso. Assim, uma planta só será útil para este fim se não afetar as culturas de importância econômica. Desta forma, pesquisas nesta linha são fundamentais para embasamento de novas tecnologias.

A este efeito direto ou indireto e danoso ou benéfico que uma planta exerce sobre a outra pela produção de compostos químicos liberados no ambiente dá-se o nome de alelopatia (RICE, 1984). A alelopatia é um dos mecanismos pelo qual plantas invasoras interferem no crescimento das outras plantas, produzindo modificações na população e no padrão da vegetação da comunidade de plantas cultivadas. Seus efeitos não só diminuem o potencial produtivo das espécies desejáveis como favorecem a disseminação de espécies indesejáveis (CASTRO; FERREIRA, 2001).

Dentre as plantas medicinais com potencial alelopático que poderiam ser mais estudadas como alternativa de controle de plantas invasoras encontram-se a carqueja e o confrei. A carqueja (Baccharis trimera Less. DC) é uma planta da família das compostas (Asteraceae), de origem brasileira (MARTIM et al., 1990). Essa é uma planta perene, subarbustiva, ereta, de caule lenhoso e trialado em toda sua extensão, nativa do Sul e Sudeste do Brasil, propagando-se principalmente por sementes (LORENZI, 2000). Também pode propagar-se por mudas retiradas de uma planta adulta por divisão de touceiras ou por estaquia. A melhor época do ano para o plantio da carqueja está entre os meses de setembro e outubro. No entanto, a cultura deve ser renovada a cada 3 a 4 anos (CASTRO; FERREIRA, 2001). Os metabólitos secundários presentes na carqueja são as lactonas diterpênicas, flavonóides, resina, saponina, vitaminas, esteróides e/ou triterpenos, polifenóis, taninos e óleos essenciais (TESKE; TRENTINI, 2001).

O confrei (Symphytum officinale L), da família Boraginaceae, é uma planta de rizoma grosso, raízes fusiformes e fasciculadas, caules eretos, ramos ásperos e angulosos. Crescem até $80 \mathrm{~cm}$, possuem flores brancacentas, tubulosas, grandes, dispostas no ápice dos ramos superiores e adaptam-se a climas frios (CONFREI, 2004). A propagação do confrei pode ser feita por divisão de touceiras, por estaquia de raízes ou de folhas e por sementes importadas (CASTRO; CHEMALE, 1995). Os metabólitos secundários presentes no confrei são as alantoínas, os taninos, açúcares, saponinas, triterpenos, vitaminas, aminoácidos essenciais, es- 
teróides, ácidos orgânicos, alcalóides pirrolizidínicos, mucilagens e fitoesteróides (TESKE; TRENTINI, 2001).

Efeitos alelopáticos foram observados em extratos aquosos de carqueja que retardam a germinação de sementes de tomate, nas quais ocorreram alterações no tempo e na velocidade média de germinação. Esses efeitos podem estar relacionados com a presença de taninos nas partes aéreas da carqueja, os quais são divididos em dois grupos: hidrolisáveis e não-hidrolisáveis. Os taninos hidrolisáveis são conhecidos por suas propriedades alelopáticas, pois atuam como inibidores da germinação de sementes, do crescimento das plantas, das bactérias fixadoras de nitrogênio e das nitrificantes. Os dois tipos de taninos são encontrados na carqueja (CASTRO; FERREIRA, 2001).

O resíduo do extrato bruto aquoso da parte aérea de carqueja ou a planta picada, ambos aplicados em cobertura, assim como plantas incorporadas no substrato reduziram significativamente a emergência e o número de folhas de tiriricas. $\mathrm{O}$ extrato de plantas de confrei também determinou menor porcentagem de emergência de tiriricas (GAZIRI; CARVALHO, 2004). Extratos aquosos da parte aérea de carqueja também apresentaram inibição de germinação de sementes de azevém e picão-preto (DEPINÉ, 2003).

No Brasil, foi encontrado que restevas de trigo (Triticum aestivum L.), aveia preta (Avena strigosa Schreb) ou centeio (Secale cereale L) não influíram sobre a germinação de culturas de verão como milho, feijão e soja, mas afetaram 0 crescimento desta plantas (RODRIGUES et al., 1999). Igualmente, restos de plantas de soja ou azevém inibiram o desenvolvimento das raízes de milho em até 34\% (MARTIM et al., 1990). Restos de palhada de arroz podem inibir o crescimento de aveia, trigo e lentilha (NARWAL, 1999).

O objetivo desta pesquisa foi avaliar o efeito alelopático dos extratos brutos aquosos da parte aérea de plantas de carqueja e de plantas inteiras de confrei sobre a germinação de sementes e crescimento de plântulas de soja e milho.

\section{Materiais e métodos}

Esta pesquisa foi realizada no Laboratório de Análise de Sementes do Campus São José dos Pinhais, da Pontifícia Universidade Católica do
Paraná, localizada no município de São José dos Pinhais, Paraná.

Após a coleta das plantas de carqueja e confrei, utilizando tesoura de poda, foi preparado o extrato bruto aquoso (EBA) por meio do turbilhonamento de $200 \mathrm{~g}$ do material em liquidificador em um litro de água destilada. Foram utilizadas a parte aérea das plantas de carqueja e plantas inteiras de confrei para preparo do EBA. Por meio da diluição desta solução, obtiveram-se as soluções de concentração menor.

Os tratamentos adotados foram cinco concentrações de EBA:

- T1: 0 g. $\mathrm{L}^{-1}$

- T2: 50 g. $\mathrm{L}^{-1}$

- T3: 100 g. $\mathrm{L}^{-1}$

- T4: $150 \mathrm{~g} . \mathrm{L}^{-1}$

- T5: 200 g. $\mathrm{L}^{-1}$

Utilizaram-se quatro repetições, totalizando vinte parcelas para cada cultura de soja e milho.

O método de germinação utilizado para as sementes de soja (variedade BRS 132) e milho (variedade Pionner 3063) foi o de rolo de papel acondicionado em germinadora com temperatura de $25^{\circ} \mathrm{C}$ por um período de sete dias. Foram utilizados dois rolos de papel com 50 sementes, totalizando 100 sementes por parcela. Os rolos de papel foram todos tratados por imersão nos EBAs (cinco concentrações).

As variáveis analisadas foram as seguintes: plântulas normais (\%); plântulas anormais (\%); sementes dormentes (\%); sementes duras (\%); e sementes mortas (\%).

Os critérios de avaliação de anormalidades de plântulas foram adotados conforme recomendação da Regra para Análise de Sementes (BRASIL, 1992) que estabelece detalhadamente todos os tipos de anormalidade em plântulas de monocotiledôneas e dicotiledôneas.

As sementes dormentes são aquelas que ao final do teste de germinação apresentaram embebição com água, mas não germinaram. As sementes duras foram aquelas que não apresentaram embebição e as sementes mortas foram aquelas que se apresentaram em fase adiantada de deterioração.

O delineamento experimental adotado foi completamente casualisado com cinco tratamen- 
tos e quatro repetições. As médias dos tratamentos com diferença significativa pelo " $\mathrm{F}$ " teste na análise de variância foram submetidos à análise de regressão. Os experimentos com soja e milho bem como com as duas plantas medicinais foram analisadas separadamente, totalizando quatro experimentos.

\section{Resultados}

No experimento com sementes de milho tratadas com extrato bruto aquoso de plantas inteiras de confrei, ocorreu redução da porcentagem de plântulas normais, mais significativa quando utilizadas as concentrações de EBA acima de 100 g.L $\mathrm{L}^{-1}$ (GRÁFICO 1). Porém, não houve aumento da porcentagem de plântulas anormais e as principais anormalidades observadas, mesmo nas semen- tes testemunhas, foram raiz primária curta, ausência de raiz primária e coleóptilo com fendas. Por outro lado, foi observado também aumento linear da porcentagem de sementes dormentes com 0 aumento da concentração do EBA. Até 100 g.L $\mathrm{L}^{-1}$ de extrato, a interferência na germinação das sementes foi pequena, porém mesmo nas concentrações mais elevadas, a porcentagem de sementes dormentes foi menor que 5\% (GRÁFICO 2). A dormência de sementes também pode exprimir um efeito retardador de germinação. Não houve diferenças significativas com relação à porcentagem de sementes duras e mortas em função das diferentes concentrações de EBA utilizadas. Desta forma, os extratos de confrei com concentrações até 100 g. $\mathrm{L}^{-1}$ poderiam ser utilizados para inibição de plantas invasoras sensíveis sem interferir na germinação e estabelecimento inicial da cultura do milho.

\section{GRÁFICO 1 - Porcentagem de plântulas normais de milho após teste de germinação com diferentes concentraçoes de Extrato Bruto Aquoso (EBA) de plantas inteiras de confrei.} Graphic 1 - Percentage of normal seedlings of oorn after seeds germination test with different aqueous extract concentration of comfrey entire plants.

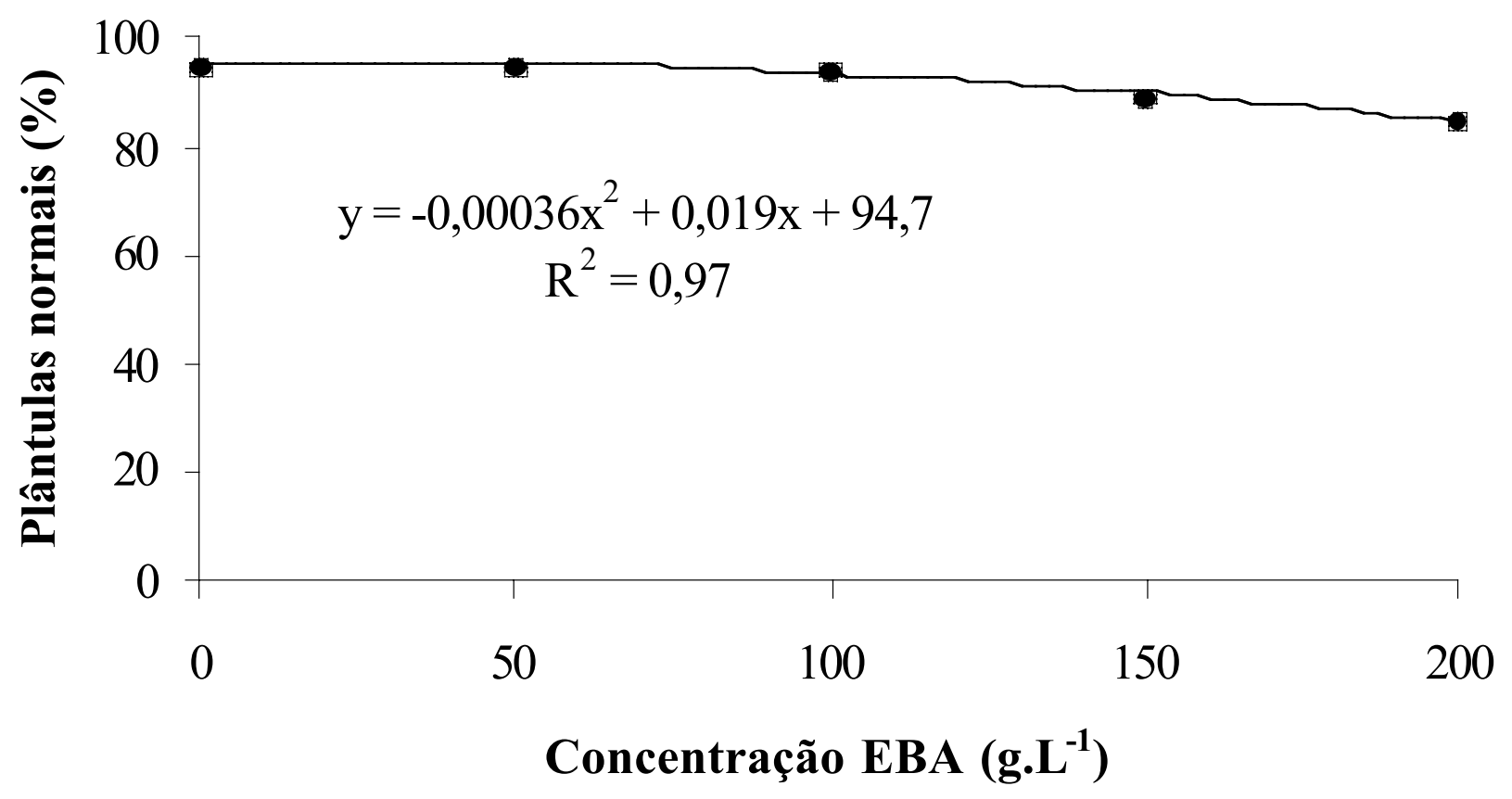


GRÁFICO 2 - Porcentagem de sementes dormentes de milho após teste de germinação com diferentes concentraçóes de Extrato Bruto Aquoso (EBA) de plantas inteiras de confrei. Graphic 2 - Percentage of dormant seeds of corn after seeds germination test with different aqueous extract concentration of comfrey entire plants.

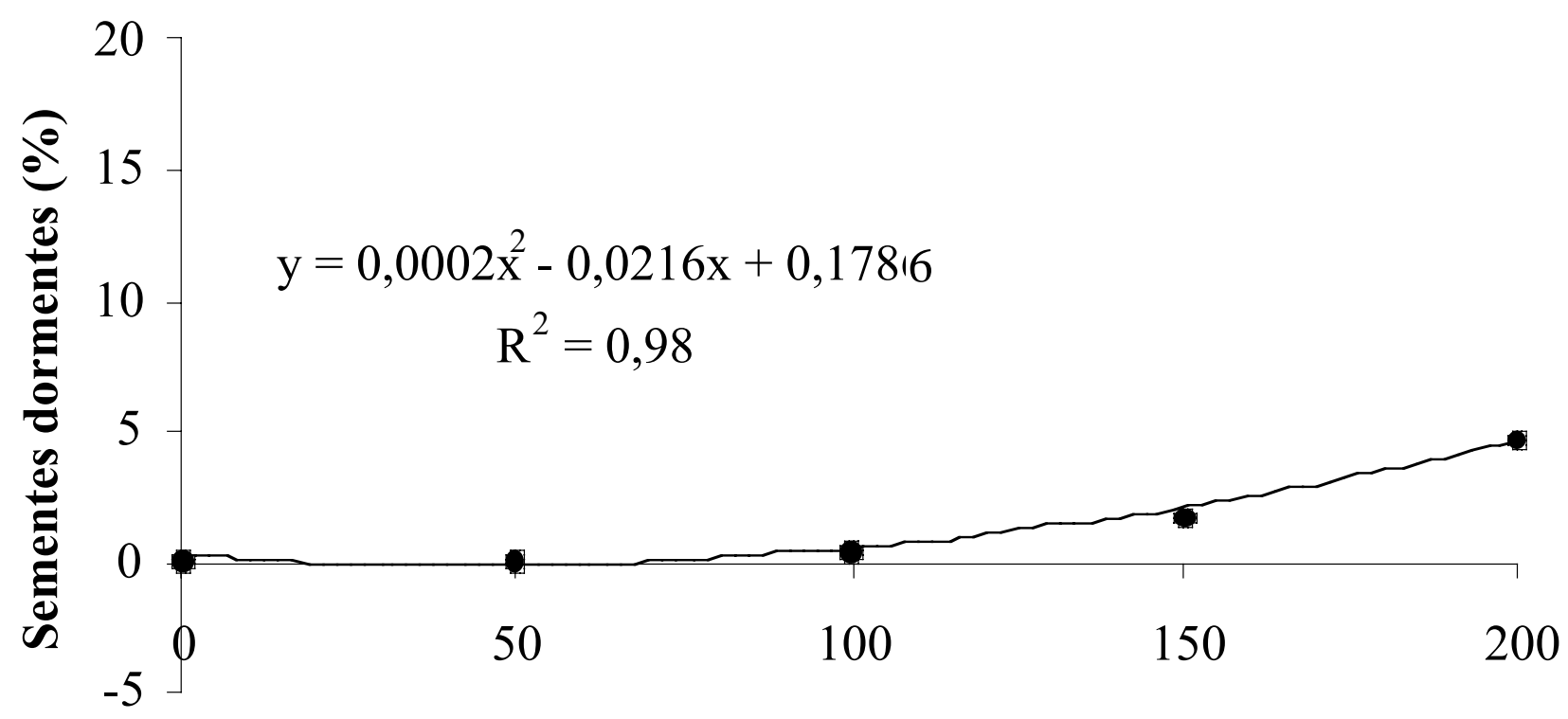

Concentração EBA (g.L $\left.{ }^{-1}\right)$

No experimento com sementes de soja tratadas com extrato bruto aquoso de plantas inteiras de confrei foi observado que, com o aumento da concentração do extrato, houve significativa redução da porcentagem de plântulas normais e aumento da porcentagem de plântulas anormais (GRÁFICOS 3 e 4), devendo ser dada maior atenção à principal anormalidade observada que foi o hipocótilo enrolado (GRÁFICO 5). Outras anormalidades como ausência de raiz primária, hipocótilo com fendas, dano na união entre cotilédones e broto terminal, ausência de cotilédones e hipocótilo curto e grosso foram observadas, mas não foram significativas. Não houve problemas de ausência de germinação, ou seja, as sementes germinaram normalmente sem o aparecimento de sementes dormentes, duras ou mortas. Devido à significativa interferência dos extratos na germinação das sementes, os extratos de confrei não poderiam ser utilizados na inibição de plantas invasoras na cultura da soja. 
GRÁFICO 3 - Porcentagem de plântulas normais de soja após teste de germinação com diferentes concentrações de Extrato Bruto Aquoso (EBA) de plantas inteiras de confrei. Graphic 3 - Percentage of normal seedlings of soybean after seeds germination test with different aqueous extract concentration of comfrey entire plants.

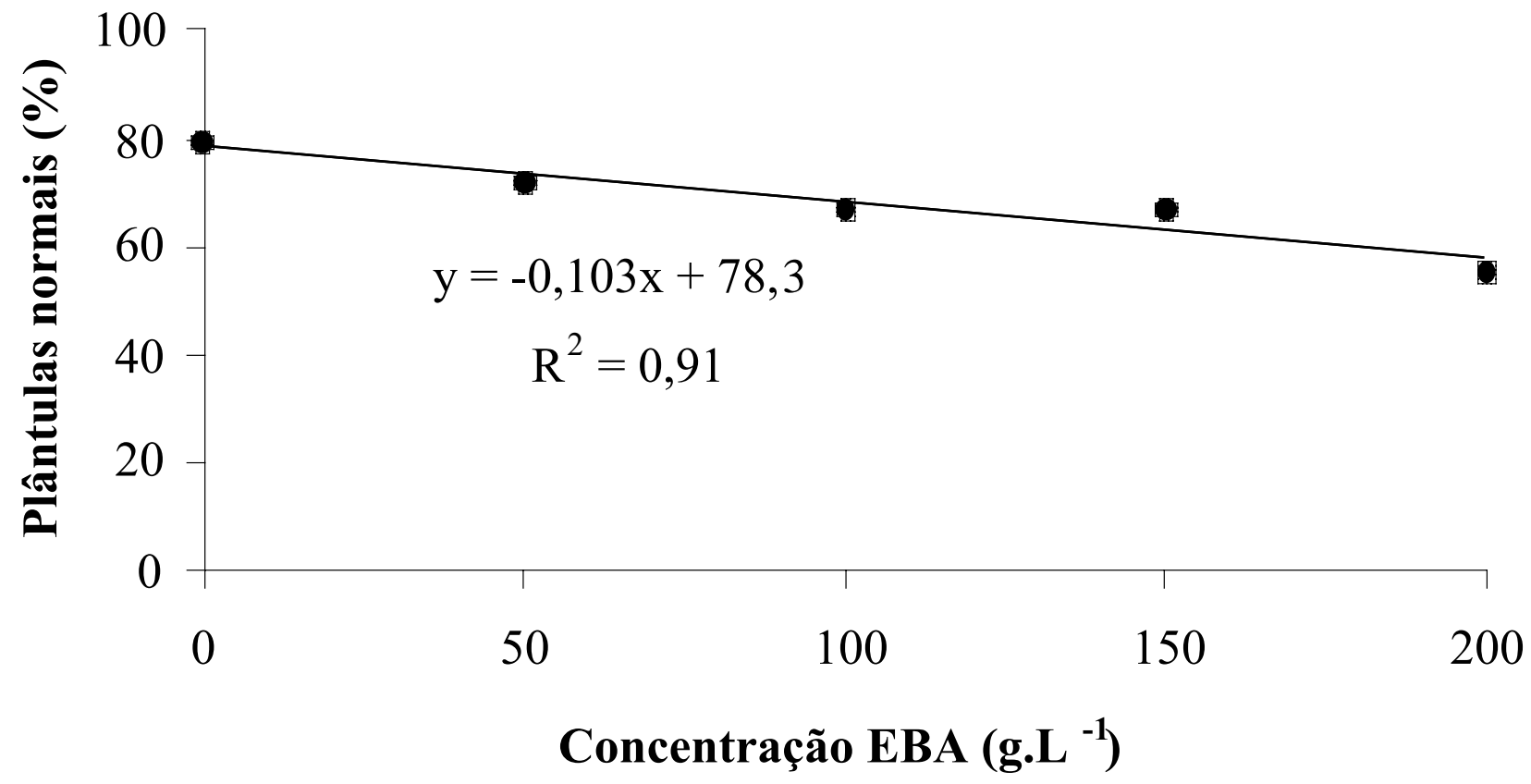

GRÁFICO 4 - Porcentagem de plântulas anormais de soja após teste de germinação com diferentes concentraçôes de Extrato Bruto Aquoso (EBA) de plantas inteiras de confrei. Graphic 4 - Percentage of abnormal seedlings of soybean after seed germination test with different aqueous extract concentration of comfrey entire plants.

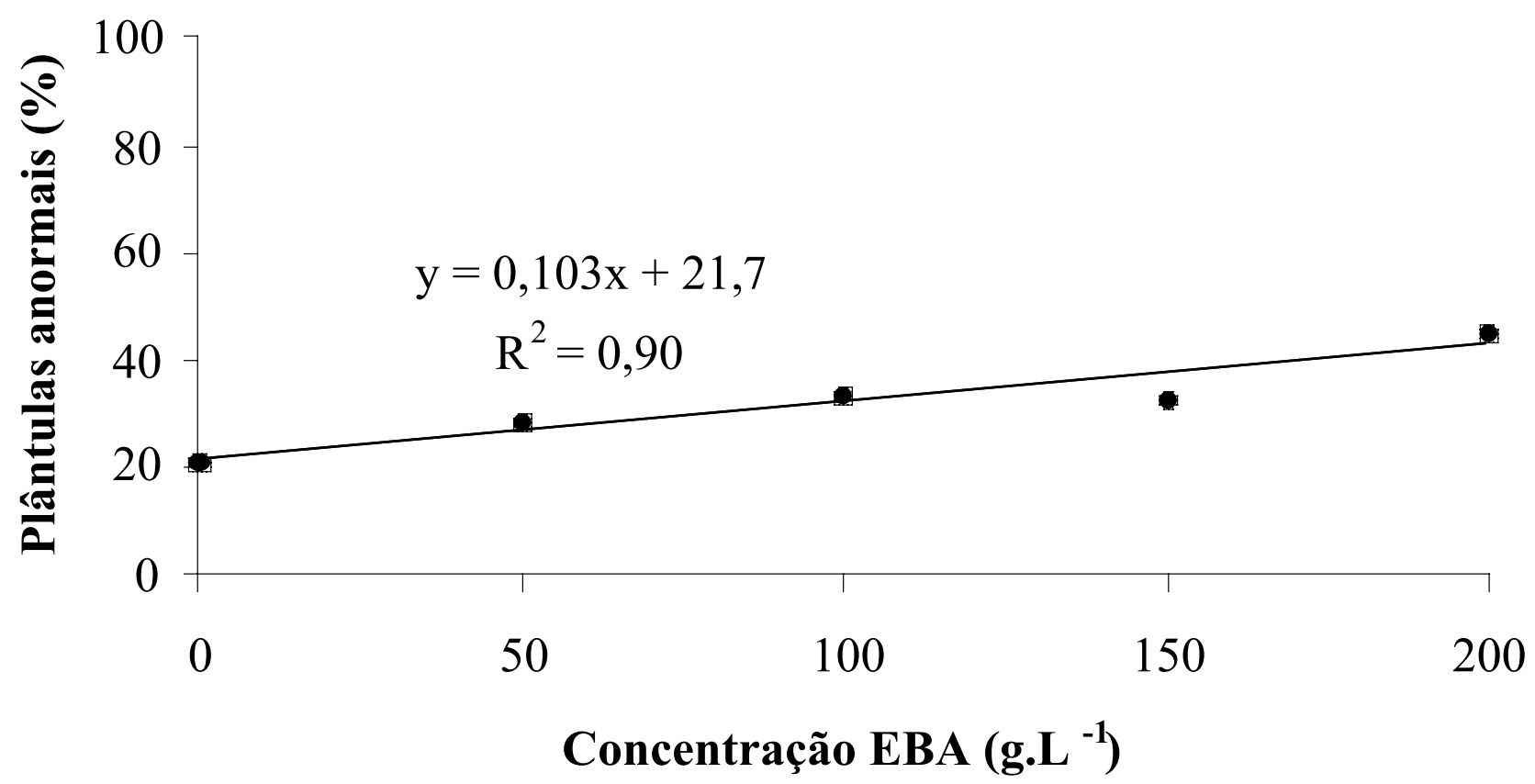


GRÁFICO 5 - Porcentagem de plântulas anormais de soja, com hipocótilo enrolado, após teste de germinação com diferentes concentrações de Extrato Bruto Aquoso (EBA) de plantas inteiras de confrei.

Graphic 5 - Percentage of abnormal seedlings of soybean with hypocotyl rolling up after seed germination test with different aqueous extract conœentration of comfrey entire plants.

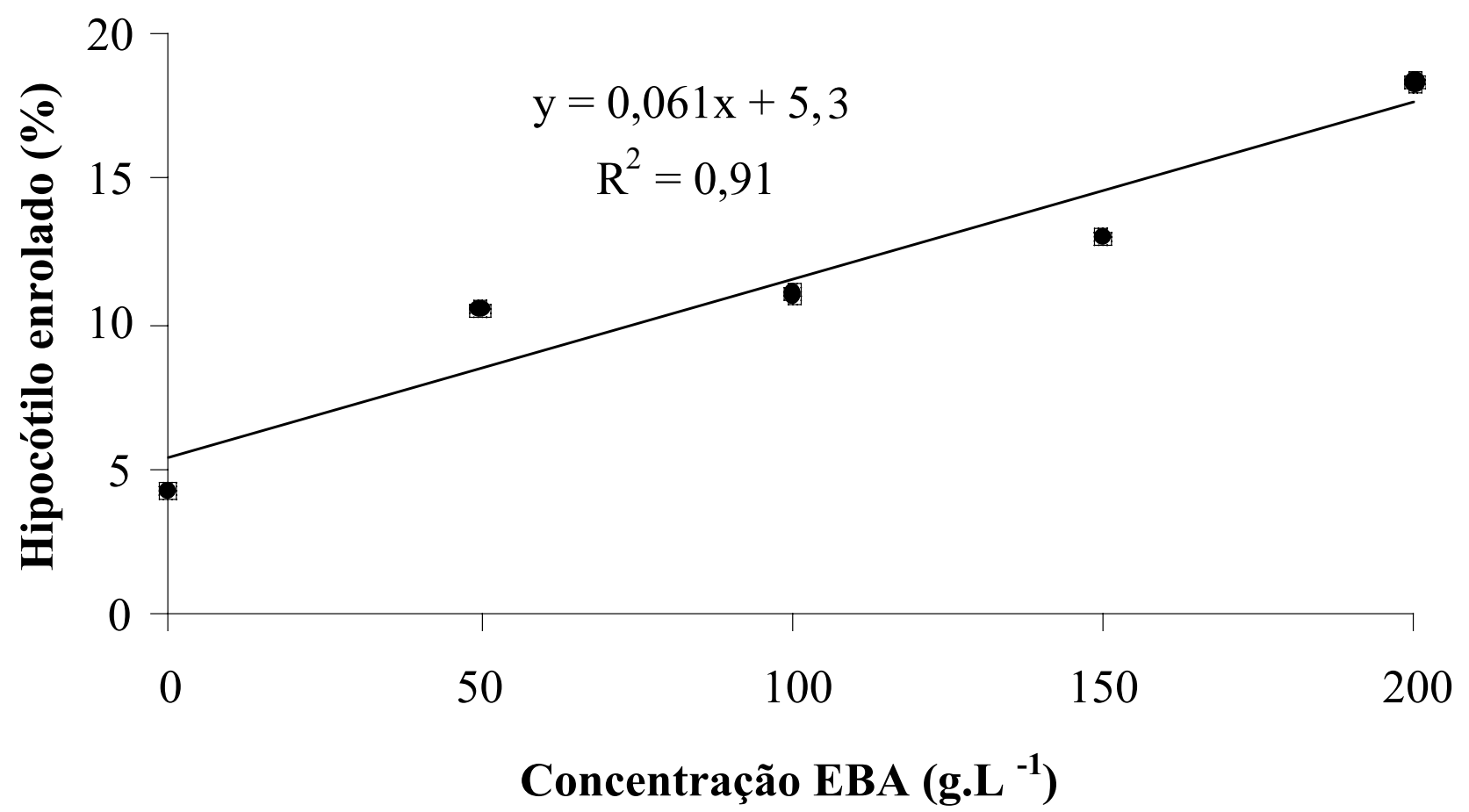

No experimento com sementes de milho tratadas com extrato bruto aquoso da parte aérea de plantas de carqueja, também houve interferência no desenvolvimento das plântulas, como a redução da porcentagem de plântulas normais (GRÁFICO 6) e aumento da porcentagem de plântulas anormais (GRÁFICO 7). A principal anormalidade apontada nas plântulas foi a de raiz primária curta, cuja ocorrência aumentou significativamente com o aumento da con- centração do extrato (GRÁFICO 8). Outras anormalidades também foram observadas como plântulas sem raízes seminais e plântulas com coleóptilo com fendas, sendo os resultados destes não significativos. As sementes germinaram normalmente, não havendo a constatação de sementes dormentes, duras ou mortas. Os resultados sugerem que os extratos de carqueja não poderiam ser utilizados na inibição de plantas invasoras na cultura do milho. 
GRÁFICO 6 - Porcentagem de plântulas normais de milho após teste de germinação com diferentes concentraçôes de Extrato Bruto Aquoso (EBA) com parte aérea de plantas de carqueja.

Graphic 6 - Percentage of normal seedlings of corn after seed germination test with different aqueous extract concentration of aerial part of carqueja.

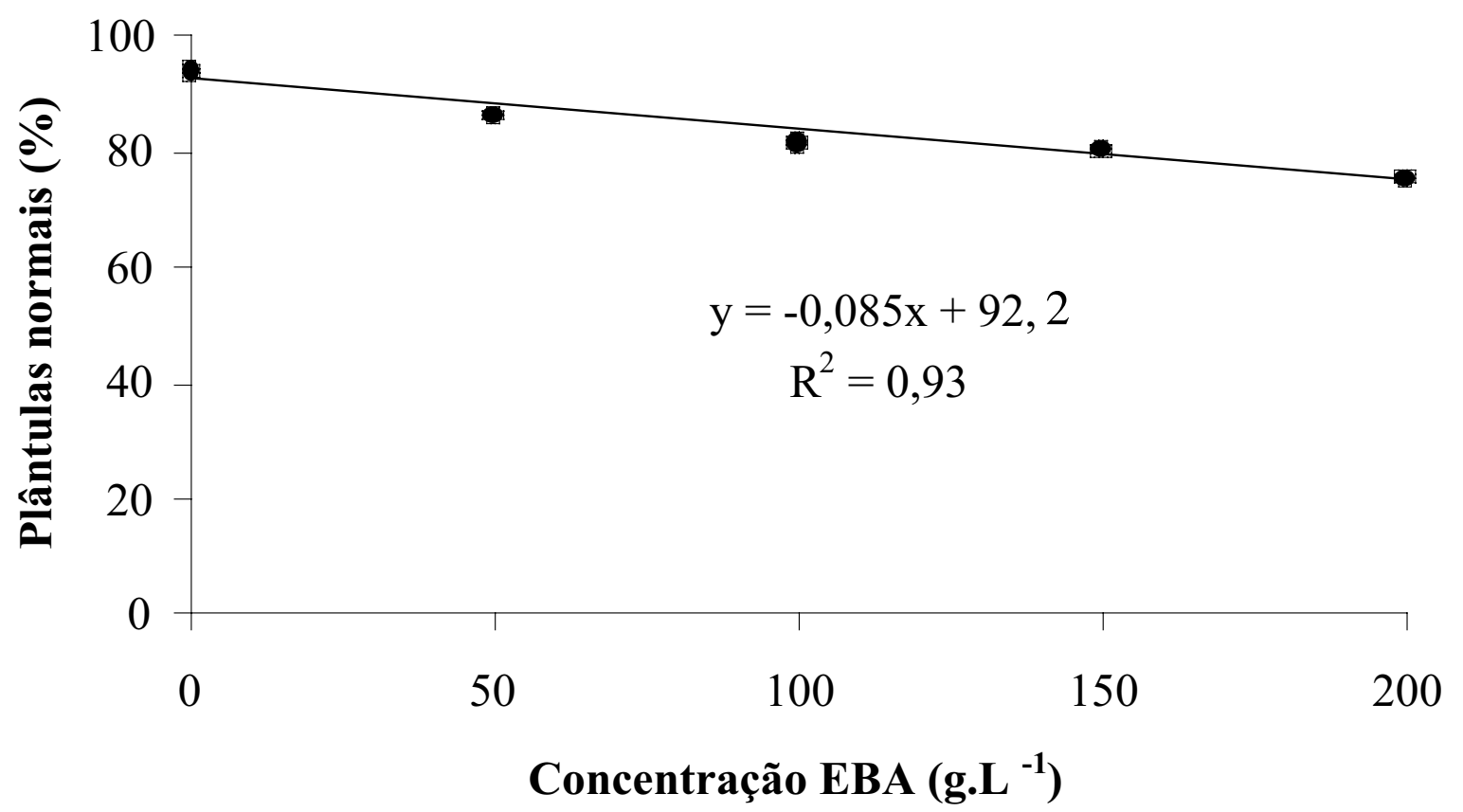

GRÁFICO 7 - Porcentagem de plântulas anormais de milho após teste de germinação com diferentes concentraçôes de Extrato Bruto Aquoso (EBA) com parte aérea de plantas de carqueja.

Graphic 7 - Perœentage of abnormal seedlings of corn after seed germination test with different aqueous extract concentration of aerial part of carqueja.

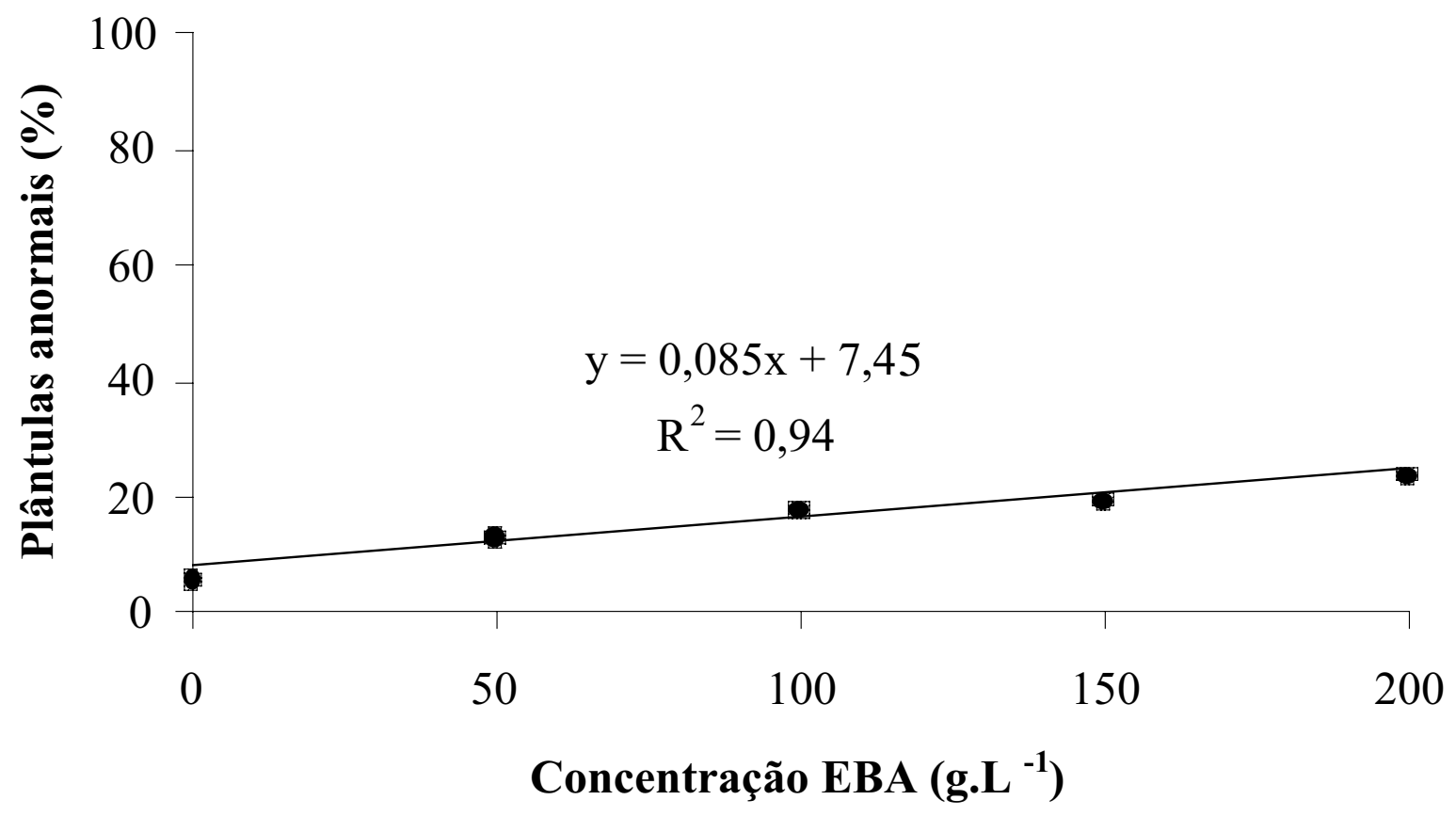


GRÁFICO 8 - Porcentagem de plântulas anormais de milho, com raízes curtas, após teste de germinação com diferentes concentrações de Extrato Bruto Aquoso (EBA) com parte aérea de plantas de carqueja.

Graphic 8 - Percentage of abnormal seedlings of corn with short roots after seed germination test with different aqueous extract concentration of aerial part of carqueja.

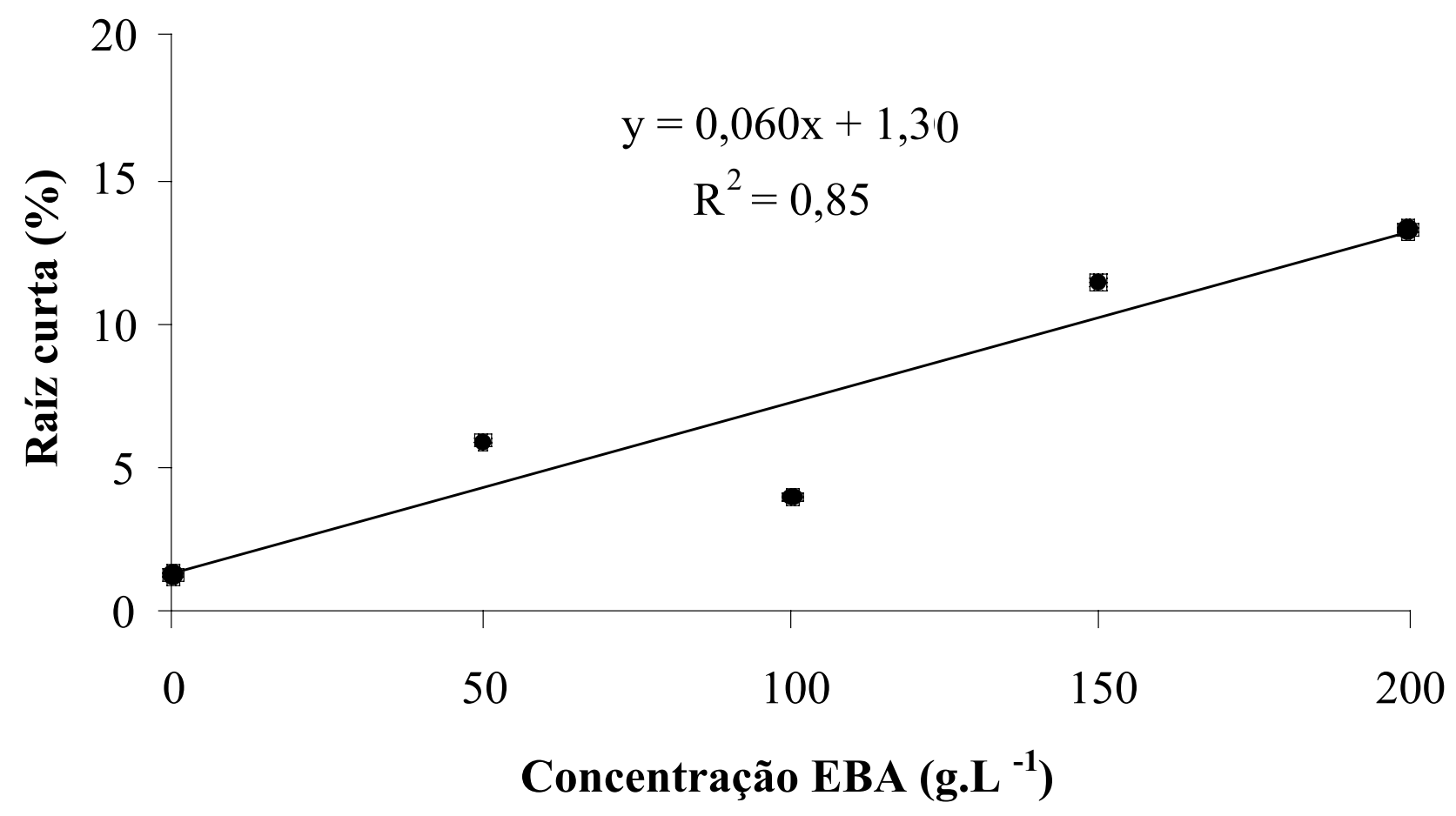

No experimento com sementes de soja tratadas com extrato bruto aquoso de parte aérea de plantas de carqueja, foi observado que até 100 g. $\mathrm{L}^{-1}$ de concentração de extrato, as interferências na redução de plântulas normais e na elevação de plântulas anormais foram pequenas (GRÁFICO 9 e 10), mas com o aumento da concentração a porcentagem de anormalidades se elevou. Houve aumento linear da anormalidade hipocótilo curto das plântulas de soja (GRÁFICO 11) e aumento quadrático da porcentagem de plântulas com hipocótilo enrolado (GRAFICO 12). Nas concentrações de extrato acima de
100 g.L $\mathrm{L}^{-1}$ a ocorrência da anormalidade elevouse rapidamente. Foram observadas também outras anormalidades, como plântulas sem raiz primária, hipocótilo com fendas e dano na união entre cotilédones e broto terminal com resultados pouco expressivos. A germinação das sementes ocorreu normalmente sem o surgimento de sementes dormentes, duras ou mortas. Desta forma, os extratos de carqueja com concentrações até 100 g.L ${ }^{1}$ poderiam ser utilizados para inibição de plantas invasoras sensíveis sem interferir na germinação e estabelecimento inicial da cultura da soja. 
GRÁFICO 9 - Porcentagem de plântulas normais de soja após teste de germinação com diferentes concentraçôes de Extrato Bruto Aquoso (EBA) com parte aérea de plantas de carqueja.

Graphic 9 - Percentage of normal seedlings of soybean after seed germination test with different aqueous extract concentration of aerial part of carqueja.

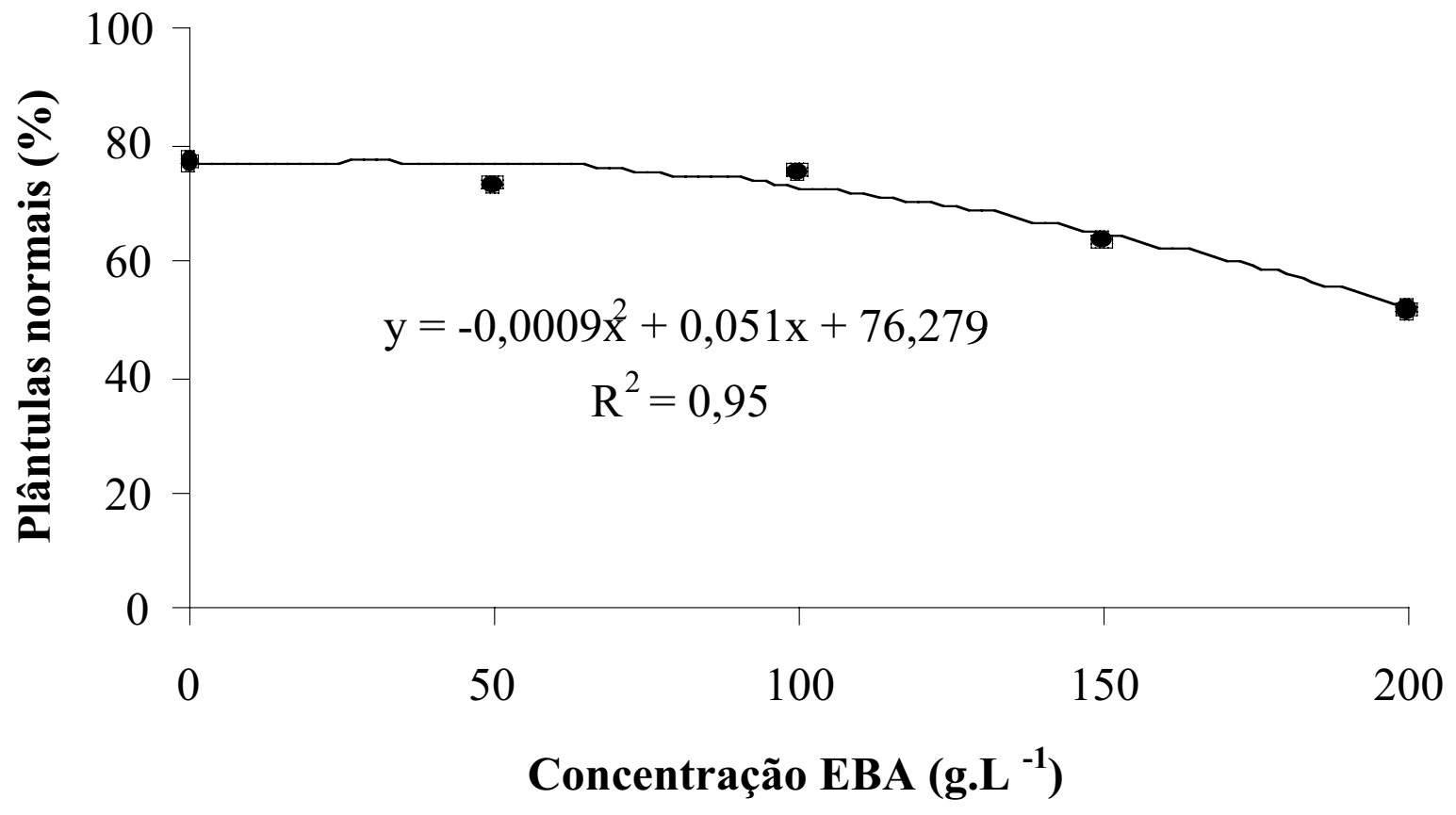

GRÁFICO 10 - Porcentagem de plântulas anormais de soja após teste de germinação com diferentes concentrações de Extrato Bruto Aquoso (EBA) com parte aérea de plantas de carqueja.

Graphic 10 - Perœentage of abnormal seedlings of soybean after seed germination test with different aqueous extract concentration of aerial part of carqueja.

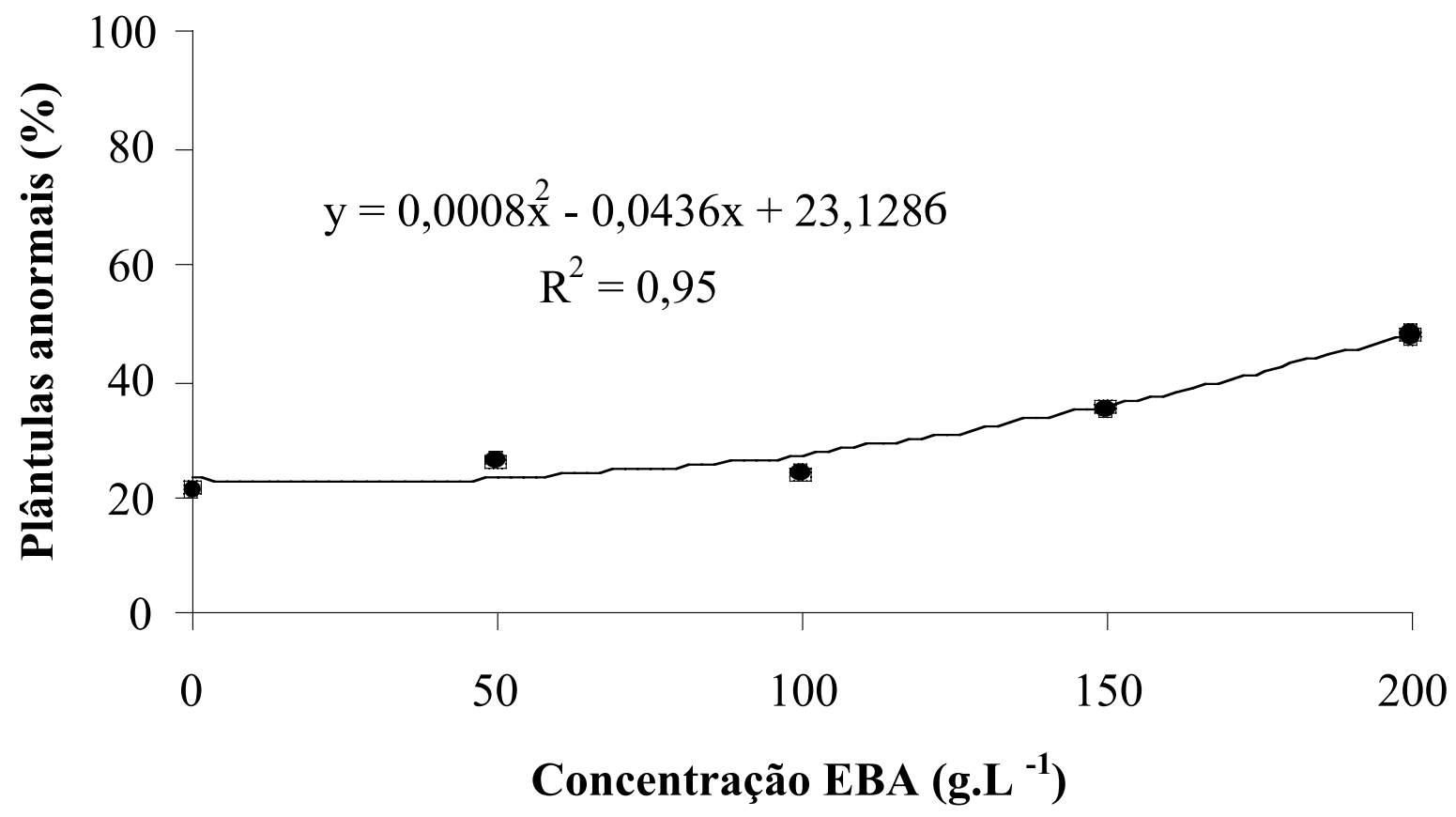


GRÁFICO 11 - Porcentagem de plântulas anormais de soja, com hipocótilo curto, após teste de germinação com diferentes concentrações de Extrato Bruto Aquoso (EBA) com parte aérea de plantas de carqueja.

Graphic 11 - Percentage of abnormal seedlings of soybean with short hypocotyl after seed germination test with different aqueous extract concentration of aerial part of "carqueja".

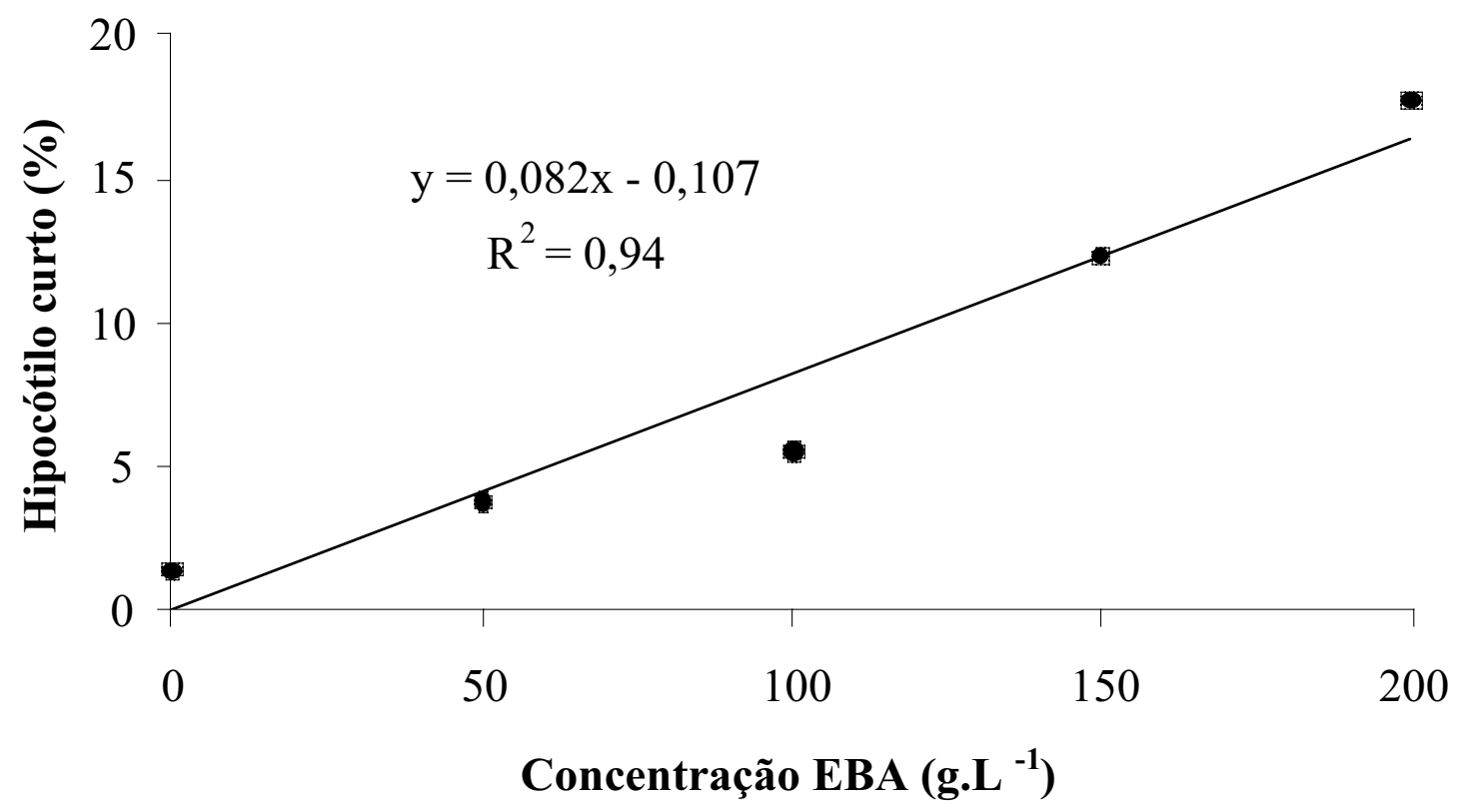

GRÁFICO 12 - Porcentagem de plântulas anormais de soja, com hipocótilo enrolado, após teste de germinação com diferentes concentrações de Extrato Bruto Aquoso (EBA) com parte aérea de plantas de carqueja.

Graphic 12 - Percentage of abnormal seedlings of soybean with hypoctyl rolling up after seed germination test with different aqueous extract conœentration of aerial part of "carqueja".

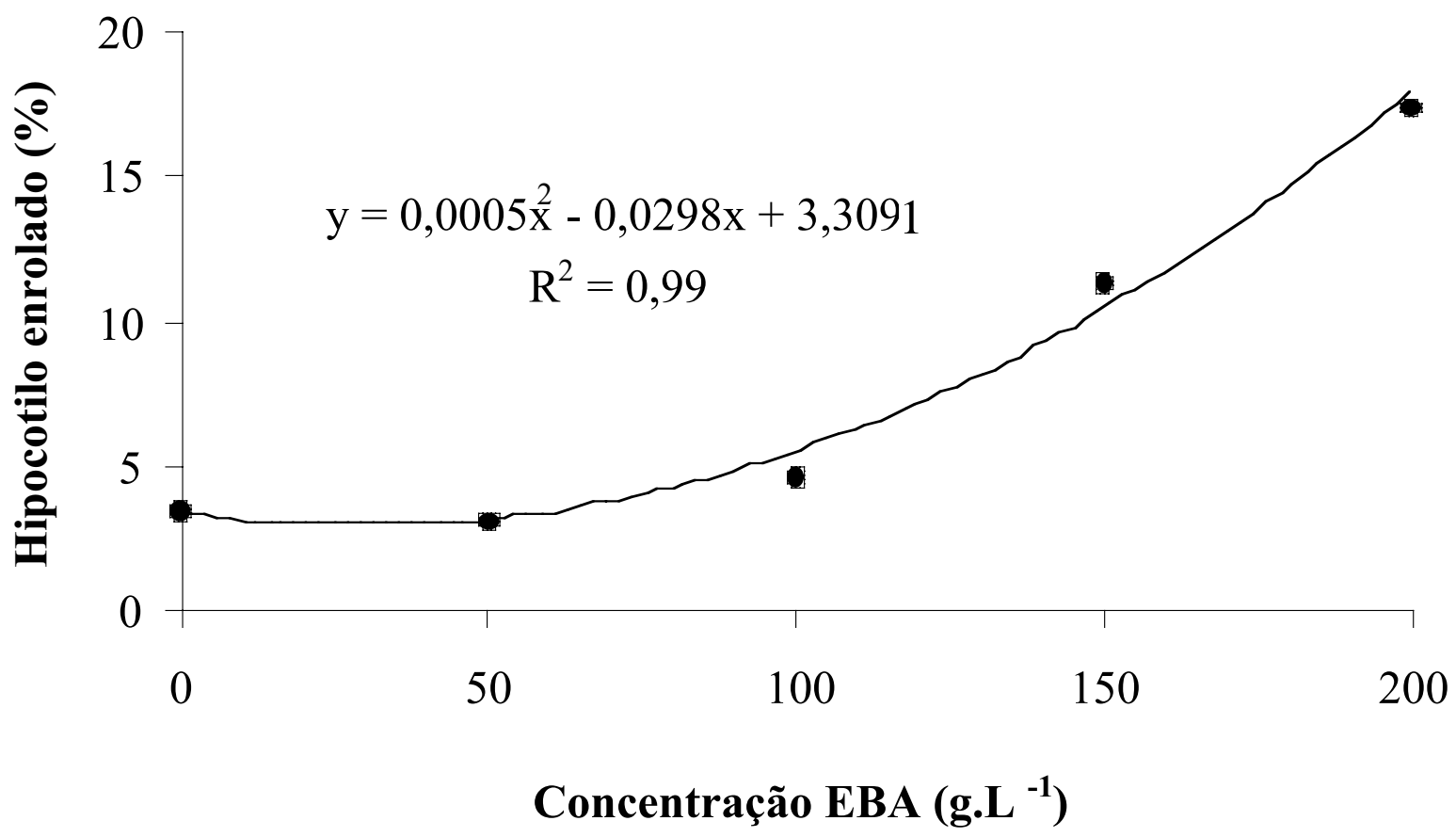




\section{Considerações finais}

Houve efeito alelopático do extrato bruto aquoso de plantas inteiras de confrei na germinação de sementes de milho, de forma mais significativa quando utilizadas concentrações acima de 100 g.L- ${ }^{-1}$.

Houve efeitos alelopáticos significativos do extrato bruto aquoso de plantas inteiras de confrei na germinação e crescimento de plântulas de soja e do extrato bruto aquoso da parte aérea de plantas de carqueja na germinação e crescimento de plântulas de milho, mesmo em concentrações baixas.

Houve efeito alelopático significativo do extrato bruto aquoso da parte aérea de plantas de carqueja na germinação e crescimento de plântulas de soja, de forma mais significativa quando utilizadas concentrações acima de 100 g. $\mathrm{L}^{-1}$.

\section{Referências}

BRASIL. Ministério da Agricultura, Reforma Agrária: Regras para análise de sementes. Brasília: SNAD / DNDV / CLAV, 1992. p. 35.

CASTRO, L. O.; CHEMALLE, V. M. Plantas Medicinais: condimentares e aromáticas. Guaíba, Agropecuária, 1995. p. 196.

CASTRO , H. G.; FERREIRA, F. A.. Contribuição ao estudo das plantas medicinais: Carqueja (Baccharis genistelloidediçosa: Suprema, 2001. p. 102.

CONFREI. Fichário. Disponível em: www.cotianet.com.br/eco/HERB/confrei. Acesso em: 18 fev. 2004.

DEPINÉ, C. Efeitos de extrato de carqueja na germinação de sementes de plantas daninhas. 2003. 43f. Monografia (Bacharelado em Ciências Biológicas) - Núcleo de Ciências Biológicas e da Saúde, Centro Universitário Positivo, Curitiba, 2003.
EMATER. Projeto Grãos Tex tos: Manejo Integrado de PlantasDaninhas. Disponívelem: www.emater.pr.gov/ HPPGraos. Acesso em: 02 mar. 2004.

FERREIRA, G. A.; ÁQUILA, M. E. A. Alelopatia: uma área emergente da ecofisiologia. Revista Brasileira de Fisiologia Vegetal, v. 12 (Edição Especial), p.175-204, 2000.

GAZIRI, L. R. B.; CARVALHO, R. I. N. Efeito alelopático de carqueja, confrei e mil-folhas sobre o desenvolvimento da tiririca. Revista Acadêmica: Ciências Agrárias e Ambientais, Curitiba, v.2, n. 4. 2004. (no prelo).

LORENZI, H. Plantas daninhas do Brasil: terrestres, aquáticas, parasitas e tóxicas. Nova Odessa: Instituto Plantarum, 2000. p. 869.

MARTIN, V. L.; MCCOY, E. L.; DICK, W. A. Allelopathy of residues influences corn seed germination and early growth. Agronomy Journal, v. 82, p. 555-560, 1990.

NARWAL, S. S. Research on allelopathy in India. In NARWAL, S. S. (Ed). Allelopathy Update, Enfield, Science Pub, 1999. v. 1. p. 123-184.

RICE, E. L Allelopathy. 2. ed. New York: Academics, 1984.

RODRIGUES, B. N.; PASSINI, T.; FERREIRA, A. G. Research on allelopathy in Brazil. In: NARWAL, S. S. Allelopathy Update. Enfield, Science Pub,1999. v. 1. p. 307-323.

TESKE, M.; TRENTINI, M. M. Herbarium compêndio de fitoterapia. 4. ed. Curitiba, Herbarium, 2001. p. 317. 